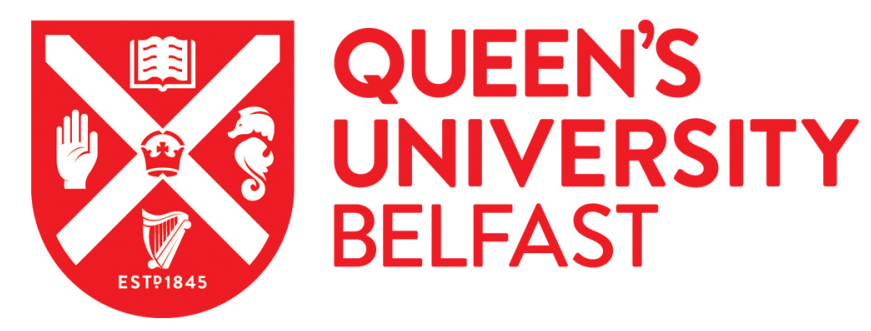

\title{
Performance enhancement of a wideband spiral antenna using a stepped ground plane
}

Mohamad, S., Cahill, R., \& Fusco, V. (2014). Performance enhancement of a wideband spiral antenna using a stepped ground plane. Microwave and Optical Technology Letters, 56(3), 753-757.

https://doi.org/10.1002/mop.28156

\section{Published in:}

Microwave and Optical Technology Letters

\section{Document Version:}

Peer reviewed version

\section{Queen's University Belfast - Research Portal:}

Link to publication record in Queen's University Belfast Research Portal

\section{Publisher rights}

Copyright $\odot 2014$ Wiley Periodicals, Inc.

This is the peer reviewed version of the following article: Mohamad, S., Cahill, R. and Fusco, V. (2014), Performance enhancement of a wideband spiral antenna using a stepped ground plane. Microw. Opt. Technol. Lett., 56: 753-757, which has been published in final form at http://onlinelibrary.wiley.com/doi/10.1002/mop.28156/abstract This article may be used for non-commercial purposes in accordance with Wiley Terms and Conditions for Self-Archiving.

\section{General rights}

Copyright for the publications made accessible via the Queen's University Belfast Research Portal is retained by the author(s) and / or other copyright owners and it is a condition of accessing these publications that users recognise and abide by the legal requirements associated with these rights.

\section{Take down policy}

The Research Portal is Queen's institutional repository that provides access to Queen's research output. Every effort has been made to ensure that content in the Research Portal does not infringe any person's rights, or applicable UK laws. If you discover content in the Research Portal that you believe breaches copyright or violates any law, please contact openaccess@qub.ac.uk. 


\section{PERFORMANCE ENHANCEMENT OF A WIDEBAND SPIRAL ANTENNA USING A STEPPED GROUND PLANE}

\begin{tabular}{|r|l|}
\hline Journal: & Microwave and Optical Technology Letters \\
\hline Manuscript ID: & Draft \\
\hline Wiley - Manuscript type: & Research Article \\
\hline Date Submitted by the Author: & n/a \\
\hline Complete List of Authors: & $\begin{array}{l}\text { mohamad, sarah; Queen's University Belfast, } \\
\text { Cahill, Robert; The Institute of Electronics, Communications and } \\
\text { Information Technology (ECIT), Queen's University Belfast } \\
\text { Fusco, Vincent; The ECIT Institute, Queens University of Belfast }\end{array}$ \\
\hline Keywords: & $\begin{array}{l}\text { spiral antennas, cavity backed antennas, UWB antennas, self- } \\
\text { complementary antennas, stepped ground plane }\end{array}$ \\
\hline &
\end{tabular}

SCHOLARONE ${ }^{\text {' }}$

Manuscripts 


\title{
Performance Enhancement of a Wideband Spiral Antenna using a Stepped Ground Plane
}

\author{
Sarah Mohamad, Robert Cahill and Vincent Fusco \\ The Institute of Electronics, Communications and Information Technology, \\ Queen's University Belfast, Northern Ireland Science Park, Queen's Road, Queen's Island, \\ Belfast, BT3 9DT, Northern Ireland, UK \\ Email: smohamad02@qub.ac.uk
}

Key Words: Spiral antennas, cavity backed antennas, UWB antennas, self-complementary antennas, stepped ground plane, active region

\begin{abstract}
This study presents the use of a stepped ground plane as a means to increase the gain and front-toback ratio of an Archimedean spiral which operates in the frequency range $3-10 \mathrm{GHz}$. The backing structure is designed to optimize the antenna performance in discrete $1 \mathrm{GHz}$ bands by placing each of the 8 metal steps one quarter wavelength below the corresponding active regions of the spiral. Simulated and experimental results show that this type of ground plane can be designed to enhance the antenna performance over the entire $105 \%$ operating bandwidth of the spiral.
\end{abstract}

\section{INTRODUCTION}

Spiral antennas exhibit constant input impedance and generate bidirectional circularly polarized radiation over a wide frequency bandwidth [1], [2]. However for many applications unidirectional operation is required, and this is normally obtained by placing an absorber filled cavity below the spiral aperture to suppress the backlobe radiation. The disadvantage of this approach is that the radiation efficiency of the antenna is reduced by about $50 \%$. Another option is to back the spiral with 
a planar metal reflector [3]. This can potentially increase the gain of the antenna by $3 \mathrm{~dB}$, however for broadband operation it is essential to maintain one quarter wavelength separation between the ground plane and aperture at all frequencies in order to prevent impedance mismatch and pattern degradation, namely a reduction in the gain and polarization purity of the antenna [3].

Ground planes consisting of conical shaped [4], [5], single step [6], and small metal plate [7] structures have been proposed as a means to enhance the performance of spirals, and these techniques have been shown to work well in two or three narrow bands within the operating frequency range of the antenna. In this paper we use a methodical approach to create a ground plane which was designed to increase the antenna gain and front-to-back (F/B) ratio of an Archimedean spiral over the entire operating frequency range $3-10 \mathrm{GHz}$. In contrast to a metal ground plane which would require mechanical tuning to maintain a constant electrical separation between the spiral and reflector, the architecture reported in this paper provides the required cavity spacing simultaneously at all frequencies and therefore enhances the gain and F/B of the spiral over the entire $105 \%$ band. The simulated VSWR, gain, front-to-back ratio and boresight axial ratio are compared to the free space (un-backed) spiral and the measured radiation patterns for both structures are presented at four frequencies including the upper and lower band edges.

\section{DESIGN OF THE ARCHIMEDEAN SPIRAL ANTENNA}

\subsection{Spiral Antenna Design}

The design of the two-arm, four-turn Archimedean spiral antenna is carried out using CST MICROWAVE STUDIO. The antenna has an outer diameter of $60 \mathrm{~mm}$ and an inner diameter of $4 \mathrm{~mm}$. The width of the arms and spacing between conductors is set to $1.65 \mathrm{~mm}$ to realize a selfcomplementary antenna. The input impedance of the spiral is therefore $188 \Omega[8]$, and in the numerical model it is center fed in anti-phase with equal amplitude signals at two excitation points which are separated by a distance $0.5 \mathrm{~mm}$. The geometry and a photograph of the RHCP copolarized 
antenna which was designed to operate in the frequency range from 3 to $10 \mathrm{GHz}$ are depicted in Figure 1.

\subsection{Stepped Ground Plane}

Most of the radiation from a spiral is attributed to the first mode of radiation [9], [10] which occurs near a circular ring around the center of the spiral whose circumference is equal to one wavelength. Therefore from band theory the radius of the active region is related to the operating frequency by $r=c / 2 \pi f$. This is shown in Figure 2 which shows the location of the highest surface current (light blue) which flows on the spiral at $3 \mathrm{GHz}$. In order to create a broadband ground plane, it is necessary to place the metal reflector $\lambda / 4$ below the physical area defined by the active region at each frequency within the operating band of the antenna. For this study the backing structure was created by positioning a metal ring one quarter wavelength below each of the eight active regions corresponding to excitations of the aperture in $1 \mathrm{GHz}$ bands from 3 to $10 \mathrm{GHz}$.

The size of each ring was determined by positioning a solid ground plane of radius $32.5 \mathrm{~mm}, \lambda / 4$ below the antenna to achieve the highest possible gain and maximum backlobe suppression. The area of the metal backing was then reduced, firstly by increasing the inner radius $r_{i}$ and then by decreasing the outer radius $r_{0}$ until a small reduction in the computed peak gain and diminished current flow on the ring surface were observed. This design process ensures that most of the energy radiated from the active region in the direction of the lower hemisphere is reflected from the surface of the ring. The antenna performance was optimized in $1 \mathrm{GHz}$ bands from 3 to $10 \mathrm{GHz}$ by using this design procedure to obtain the physical dimensions of the 8 rings which were stacked to create a stepped ground plane with the dimensions given in Table 1. The tabulated results show that the position of the active regions calculated using band theory is close to the numerical predictions. 


\section{RESULTS AND DISCUSSION}

The electromagnetic performance of the free space spiral antenna was simulated from 3 to $10 \mathrm{GHz}$ and the results compared with the stepped ground plane configuration shown in Figure 3 (b). In the numerical simulator the spiral antenna is printed on a substrate with a permittivity $\varepsilon_{\mathrm{r}}=2.2$ and thickness $\mathrm{t}=0.13 \mathrm{~mm}$ to model the Taconic TLY-5 glass reinforced PTFE material on which the antenna was printed.

The predicted VSWR (reference to a $188 \Omega$ system) of the two arrangements is plotted in Figure 4 where it is shown that the antenna in free space exhibits a flat response, and above $2 \mathrm{GHz}$ the VSWR is $<1.3$. The cavity backed antenna is less well impedance matched between $3 \mathrm{GHz}$ and $5 \mathrm{GHz}$, but the VSWR $<2$ over the entire operating band of the spiral. The gain of the spiral in free space varies between $4.1 \mathrm{~dB}_{\mathrm{ic}}(3 \mathrm{GHz})$ and $6 \mathrm{~dB}_{\mathrm{ic}}(6-10 \mathrm{GHz})$, but an increase of up to $3.1 \mathrm{~dB}$ is obtained when the stepped ground plane is placed behind the aperture. The predicted gain increase with frequency, which is shown in Figure 5, can largely be attributed to the suppression of the dominant backlobe crosspolarized (LHCP) radiation. This is quantified in Figure 6 which shows that the simulated front (RHCP) to back (LHCP) ratio of the antenna is between $8 \mathrm{~dB}$ and $22 \mathrm{~dB}$ higher when it is backed by the stacked rings. The polarization purity of the two arrangements is compared in Figure 7 where the predicted axial ratio on boresight is $<1 \mathrm{~dB}$ for the antenna in free space over the entire 3 to $10 \mathrm{GHz}$ frequency range. Scattering from the ground plane and the excitation of current which flows from the spiral ends towards the feed points is shown to increase the axial ratio, mainly between 3 and 5 $\mathrm{GHz}$. As a general observation, a similar effect is observed when a flat metal ground plane is placed below the radiating aperture [11], however the reflected currents can be suppressed by resistively loading the end of each spiral arm. In addition placing a metal reflector behind the antenna increases the modal contamination and this reduces the symmetry of the radiation patterns [11], [12]. Our computations show the effect on beam symmetry is similar for the more complex shaped ground plane formed by stacking the 8 metal rings. For brevity only the predicted copolar and crosspolar patterns for the $\phi=0^{\circ}(\mathrm{X} / \mathrm{Z})$ cut at frequencies of 3, 5, 7 and $10 \mathrm{GHz}$ are shown in Figure 
8. The spiral antenna in free space exhibits a bidirectional radiation pattern with equal gain but opposite polarizations in the forward and backward boresight directions. The polar plots clearly show the suppression of the dominant (LHCP) backlobe radiation (Figure 6) and the small increase in the boresight crosspolarisation (Figure 7) which occurs when the spiral is backed by the stepped ground plane.

The Archimedean spiral and stacked ground plane were fabricated and the circular polarized radiation patterns measured with and without the ground plane in two cuts, $\phi=0^{\circ}$ and $90^{\circ}$, in $1 \mathrm{GHz}$ increments between 3 and $10 \mathrm{GHz}$. The spiral was printed on $0.13 \mathrm{~mm}$ thick Taconic TLY-5 glass reinforced PTFE material and soldered to a $1.1 \mathrm{~mm}$ diameter semi-rigid cable which was formed to replicate the geometry of the two arms. An infinite balun arrangement [13] was used to excite the antenna at the feed points which are spaced $0.5 \mathrm{~mm}$ apart as shown in Figure 1(b). Implementation of this feed arrangement is attractive for the purpose of validating the design technique because it avoids the need to place hardware such as an impedance transformer [6] under the radiating aperture, and therefore removes the possibility of physical contact with the ring elements. Moreover although there is an impedance mismatch between the spiral (188 $\Omega$ ) and coaxial cable $(50 \Omega)$ at the feed points, this has no impact on the shape of the radiation patterns. The stepped ground plane was formed by printing the individual copper ring elements on $60 \mathrm{~mm}$ diameter, 0.13 mm thick Taconic TLY-5 substrate, and bonding these to precision cut low density foam spacers. Nylon fasteners were employed at four outer positions to align the individual conductors and clamp the stratified structure. The simulated and measured radiation patterns for the antenna in free space and positioned above the stepped ground plane are compared in Figure 8. Close agreement with the simulated polar plots is observed at all frequencies except at $3 \mathrm{GHz}$ where the backlobe suppression is noticeably lower than predicted. This can possibly be attributed to misalignment of the outermost rings (which provide the lower frequency operation of the antenna) and warping of the surface of the conductors which were printed on thin flexible foam backed substrates. The frontto-back ratio and axial ratio on boresight were obtained from the experimental radiation patterns 
and plotted in Figure 6 and 7. Copolar pattern power levels for the backed and un-backed antennas were measured in the boresight direction and the difference was used to quantify the increase in gain which is attributed to the stepped ground plane. The measured gain enhancement plotted in Figure 5 is in good agreement with the numerical simulations at the higher frequencies where the backlobe suppression and copolar pattern beamwidths are accurately modeled (Figure 8).

\section{CONCLUSIONS}

In this paper numerical and experimental results have been used to show that a carefully designed stepped ground plane can increase the gain and front-to-back ratio over the entire $3-10 \mathrm{GHz}$ operating range of a spiral antenna. The metal steps are positioned one quarter wavelength below eight active regions of the aperture which were located in discrete $1 \mathrm{GHz}$ bands. The radiation pattern performance of the proposed structure is similar to a planar metal backed reflector, but it operates without the need to mechanically reposition the ground plane to optimize the performance at each frequency. In addition the impact on the input impedance is negligible given that the transformed impedance of the backing structure is near infinite for this electrical spacing, however a performance trade-off would need to consider the small reductions in the pattern symmetry [11], [12] and polarization purity of the beam.

\section{ACKNOWLEDGEMENT}

S. Mohamad is supported by a research scholarship from International Islamic University Malaysia. 


\section{REFERENCES}

1. R.H. DuHamel and G.G. Chadwick, Frequency-independent antennas, 14-2-14, R.C. Johnson and H. Jasik, Antenna Engineering Handbook, 2nd ed., McGraw-Hill, New York, NY, 1984.

2. T.E. Morgan, $18-40 \mathrm{GHz}$ Spiral Antenna, 17th European Microwave Conference 1987 (1987), 195-200.

3. H. Nakano, K. Nogami, S. Arai, H. Mimaki, and J. Yamauchi, A spiral antenna backed by a conducting plane reflector, IEEE Trans on Antennas and Propag, 34 (1986), 791-796.

4. M.A. Acree and A.J. Prata, Archimedean spiral-mode microstrip antenna with improved axial ratio, IEEE Antennas Propag Soc Int Symp 2 (1999), 1232-1235.

5. J. Drewniak, P. Mayes, D. Tanner, and R. Waller, A log-spiral radiating-line antenna, IEEE Antennas Propag Soc Int Symp 24 (1986), 773-776.

6. P.H. Rao, M. Sreenivasan, and L. Naragani, Dual band planar spiral feed backed by a stepped ground plane cavity for satellite boresight reference antenna applications, IEEE Trans on Antennas and Propag 57 (2009), 3752-3756.

7. B. Wang and A. Chen, Design of an Archimedean spiral antenna, IEEE Conference Publications, Antennas Propag and EM Theory (2008), 348-351.

8. Y. Mushiake, Self-complementary antennas, IEEE Antennas and Propag Magazine 34 (1992), 23-29.

9. J. Kaiser, The Archimedean two-wire spiral antenna, IRE Trans on Antennas and Propag 34 (1960), 312-323.

10. C. Fumeaux, D. Baumann, and R. Vahldieck, Finite-volume time-domain analysis of a cavitybacked Archimedean spiral antenna, IEEE Trans on Antennas and Propag 54 (2006), 844851.

11. S. Mohamad, R. Cahill, and V. Fusco, Design of a cavity backed spiral antenna with improved pattern symmetry, European Conference on Antennas and Propag (EuCAP 2013). 
12. M.C. Buck and D.S. Filipovic, Spiral cavity backing effects on pattern symmetry and modal contamination, IEEE Antennas Wireless Propag Lett 5 (2006), 243-246.

13. M. Amin and R. Cahill, Side-fed bifilar helix antenna, Proc IEEE Microwave and Wireless Components Lett 15 (2005), 913-915. 


\section{FIGURE CAPTIONS}

Figure 1. (a) Archimedean spiral antenna geometrical parameters; outer diameter do $=60 \mathrm{~mm}$, inner diameter $\mathrm{di}=4 \mathrm{~mm}$, spacing $\mathrm{s}=1.65 \mathrm{~mm}$, width $\mathrm{w}=1.65 \mathrm{~mm}$, number of turns $\mathrm{N}=4$. (b) The fabricated spiral antenna fed by an infinite balun.

Figure 2. Surface current and design of the metal ring at $3 \mathrm{GHz}$.

Figure 3. Spiral antenna in (a) free space and with (b) stepped ground plane.

Figure 4. Predicted VSWR of spiral antenna in free space and placed above the stepped ground plane.

Figure 5. Predicted gain $(\mathrm{dB})$ and measured difference in gain (the measured gain in free space is normalised to provide a reference) of the spiral antenna above the stepped ground plane.

Figure 6. Predicted and measured front (copolar)-to-back (crosspolar) ratio (dB) of the spiral antenna in free space and above the stepped ground plane.

Figure 7. Predicted and measured boresight axial ratio of spiral antenna in free space and above the stepped ground plane.

Figure 8. Normalized predicted and measured right-hand circular polarized (RHCP) and left-hand circular polarized (LHCP) beams generated by the spiral antenna at $\phi=0^{\circ}$ cut in (a) free space and (b) above the stepped ground plane at frequencies $3 \mathrm{GHz}, 5 \mathrm{GHz}, 7 \mathrm{GHz}$ and $10 \mathrm{GHz}$.

\section{TABLE CAPTIONS}

Table 1. Wavelength and radius of active region (first mode) of the spiral antenna based on band theory $\left(r_{\text {circ }}\right)$ and computed optimized radius $\left(r_{0} / r_{i}\right.$ stepped GP) of the stepped ground plane at frequencies in the 3 to $10 \mathrm{GHz}$ range. 
Table 1. Wavelength and radius of active region (first mode) of the spiral antenna based on band theory $\left(r_{\text {circ }}\right)$ and computed optimized radius $\left(r_{o} / r_{i s t a p \rho a d}\right)$ of the stepped ground plane at frequencies in the 3 to $10 \mathrm{GHz}$ range.

\begin{tabular}{|c|c|c|c|}
\hline $\begin{array}{c}\text { Frequency } \\
(\mathrm{GHz})\end{array}$ & $\begin{array}{c}\lambda \\
(\mathrm{mm})\end{array}$ & $\begin{array}{c}r_{\text {cire }} \\
(\mathrm{mm})\end{array}$ & $\begin{array}{c}r_{\mathrm{o}} / r_{\text {istoppedGe }} \\
(\mathrm{mm})\end{array}$ \\
\hline 3 & 100.0 & 15.9 & $18.0 / 16.0$ \\
\hline 4 & 75.0 & 11.9 & $13.9 / 11.9$ \\
\hline 5 & 60.0 & 9.5 & $10.5 / 9.0$ \\
\hline 6 & 50.0 & 7.9 & $8.3 / 7.5$ \\
\hline 7 & 42.9 & 6.8 & $7.0 / 6.8$ \\
\hline 8 & 37.5 & 5.9 & $6.5 / 6.0$ \\
\hline 9 & 33.3 & 5.3 & $5.6 / 5.3$ \\
\hline 10 & 30.0 & 4.8 & $5.0 / 4.8$ \\
\hline
\end{tabular}

$156 \times 83 \mathrm{~mm}(96 \times 96 \mathrm{DPI})$ 


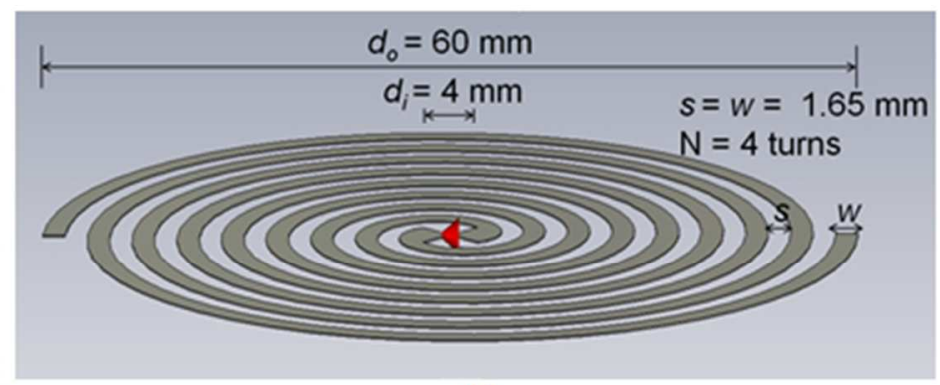

(a)

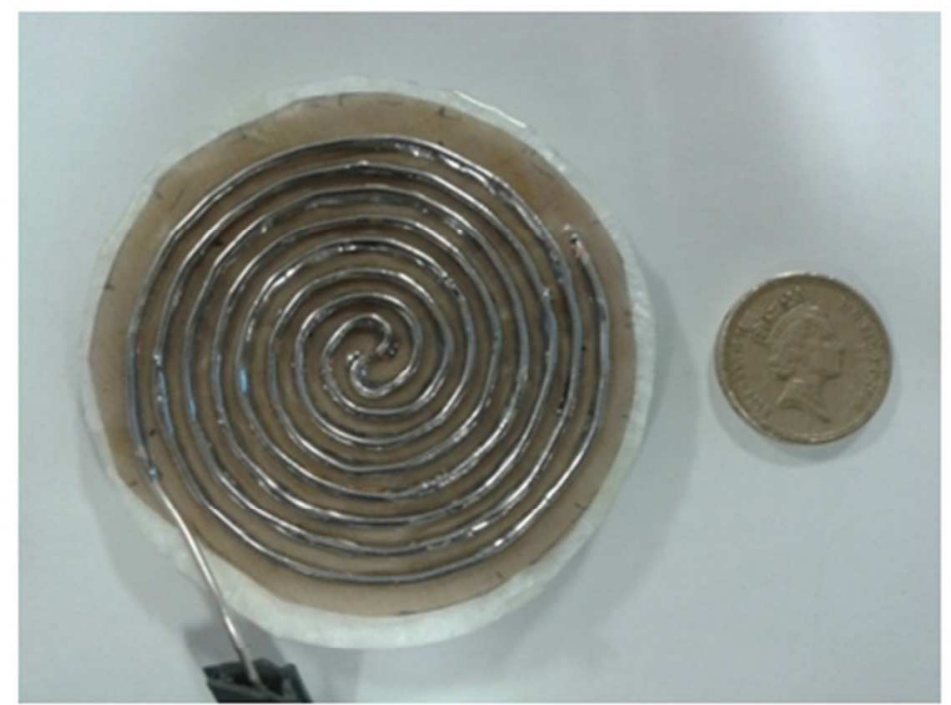

(b)

Figure 1. (a) Archimedean spiral antenna geometrical parameters; outer diameter $d_{0}=60 \mathrm{~mm}$, inner diameter $d_{i}=4 \mathrm{~mm}$, spacing $s=1.65 \mathrm{~mm}$, width $w=1.65 \mathrm{~mm}$, number of turns $N=4$

(b) The fabricated spiral antenna fed by an infinite balun

$154 \times 164 \mathrm{~mm}(96 \times 96 \mathrm{DPI})$ 


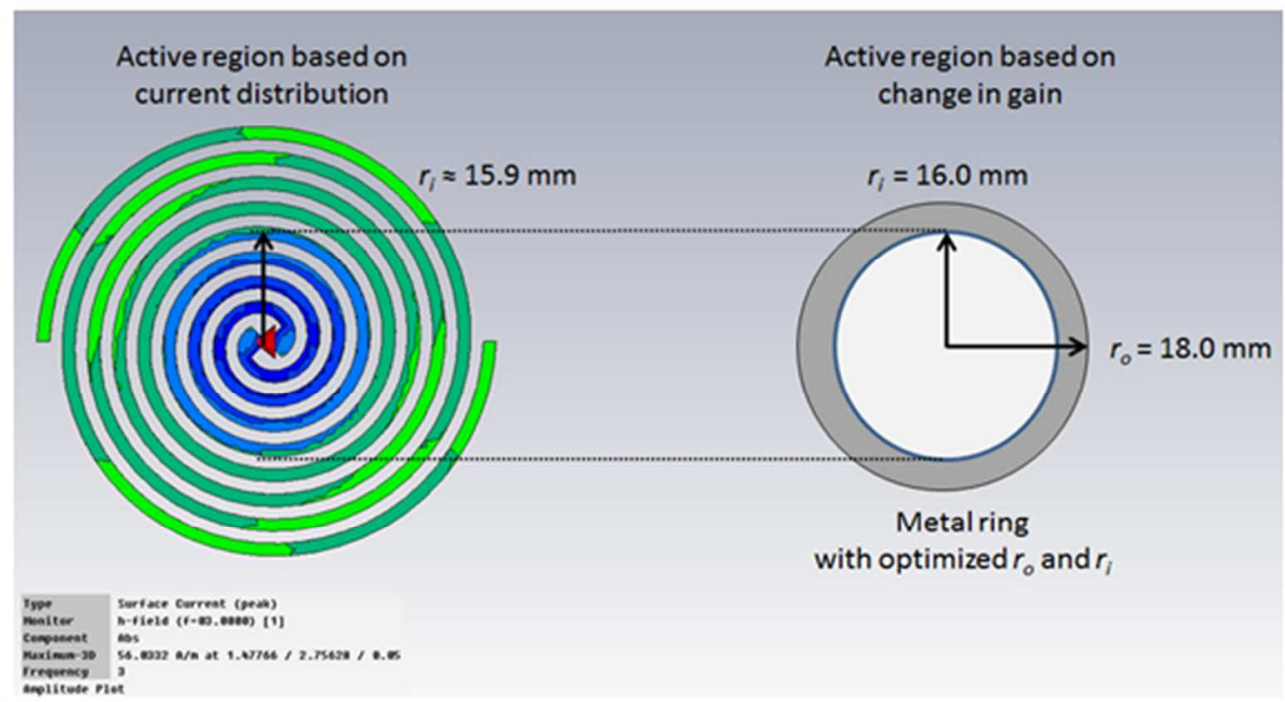

Figure 2. Surface current and design of the metal ring at $3 \mathrm{GHz}$.

$155 \times 95 \mathrm{~mm}(96 \times 96 \mathrm{DPI})$ 


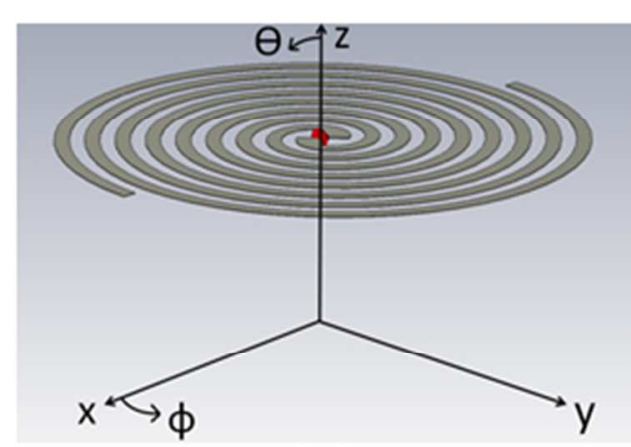

(a)

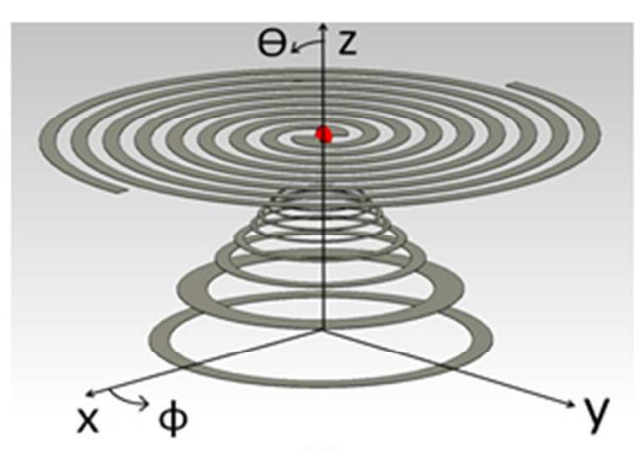

(b)

Figure 3. Spiral antenna in (a) free space and with (b) stepped ground plane.

$156 \times 70 \mathrm{~mm}(96 \times 96 \mathrm{DPI})$ 


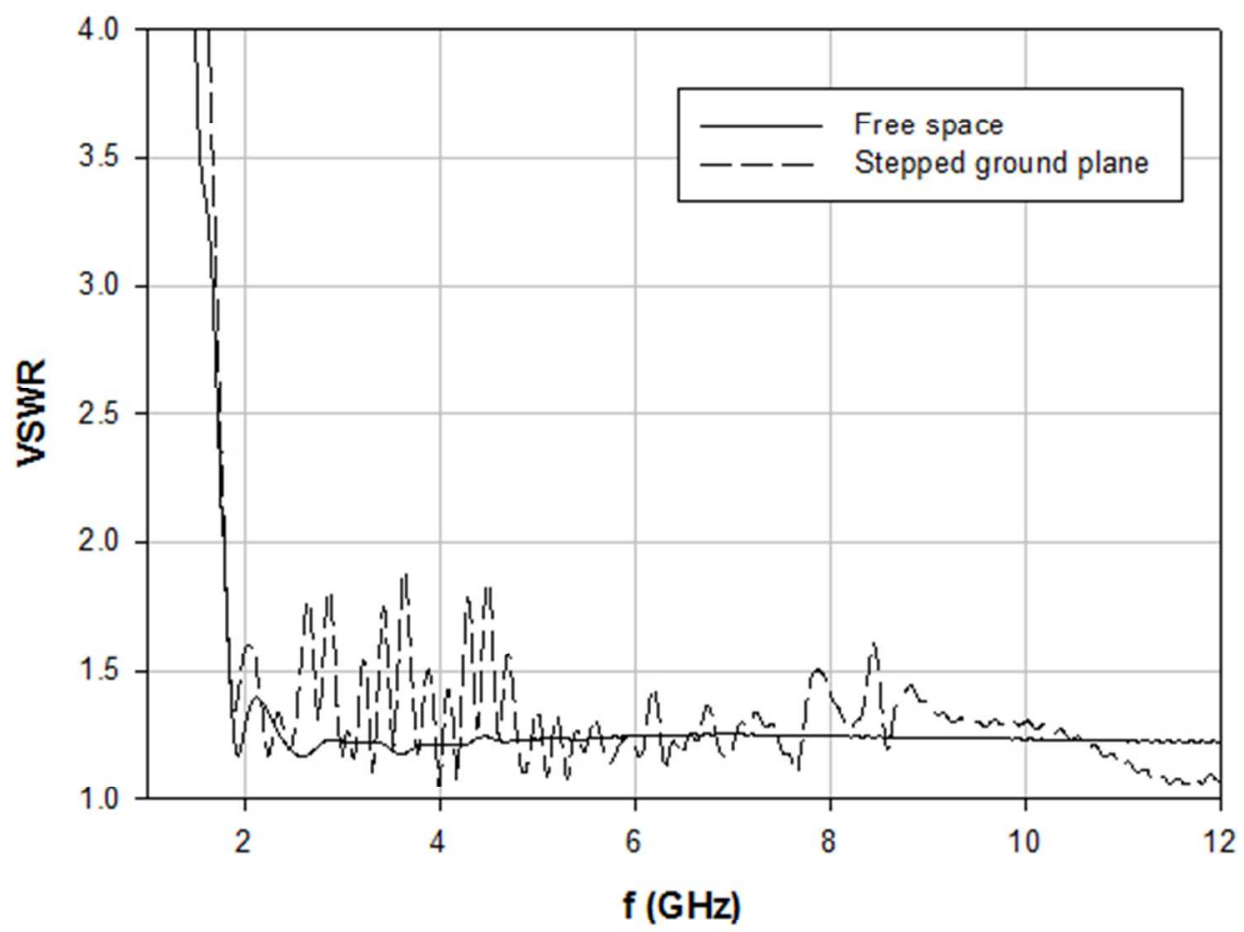

Figure 4. Predicted VSWR of spiral antenna in free space and placed above the stepped ground plane.

$151 \times 123 \mathrm{~mm}(96 \times 96 \mathrm{DPI})$ 


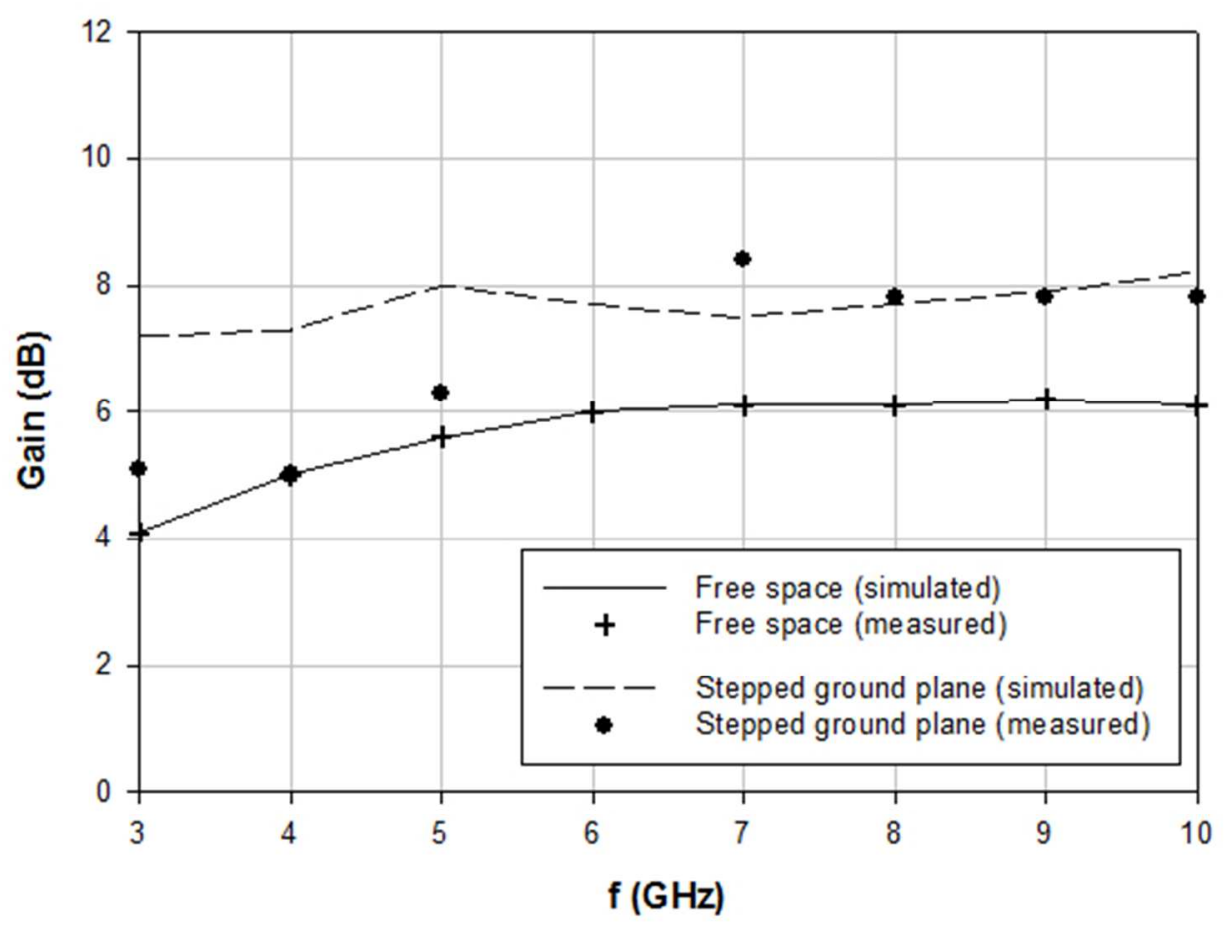

Figure 5. Predicted gain ( $\mathrm{dB}$ ) and measured difference in gain (using the antenna in free space as a reference) of the spiral antenna above a stepped ground plane.

$153 \times 129 \mathrm{~mm}(96 \times 96 \mathrm{DPI})$ 


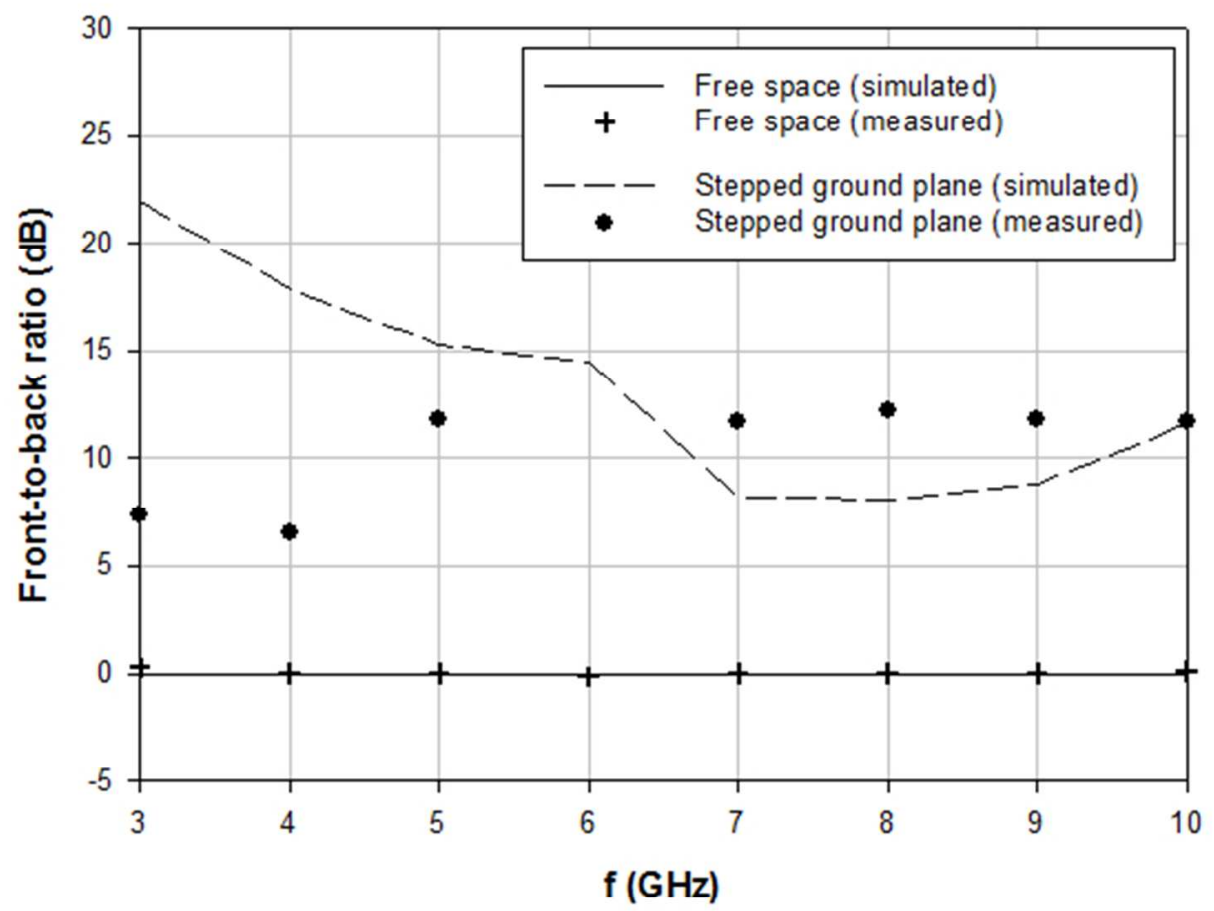

Figure 6. Predicted and measured front (copolar)-to-back (crosspolar) ratio (dB) of the spiral antenna in free space and stepped ground plane.

$155 \times 123 \mathrm{~mm}(96 \times 96 \mathrm{DPI})$ 


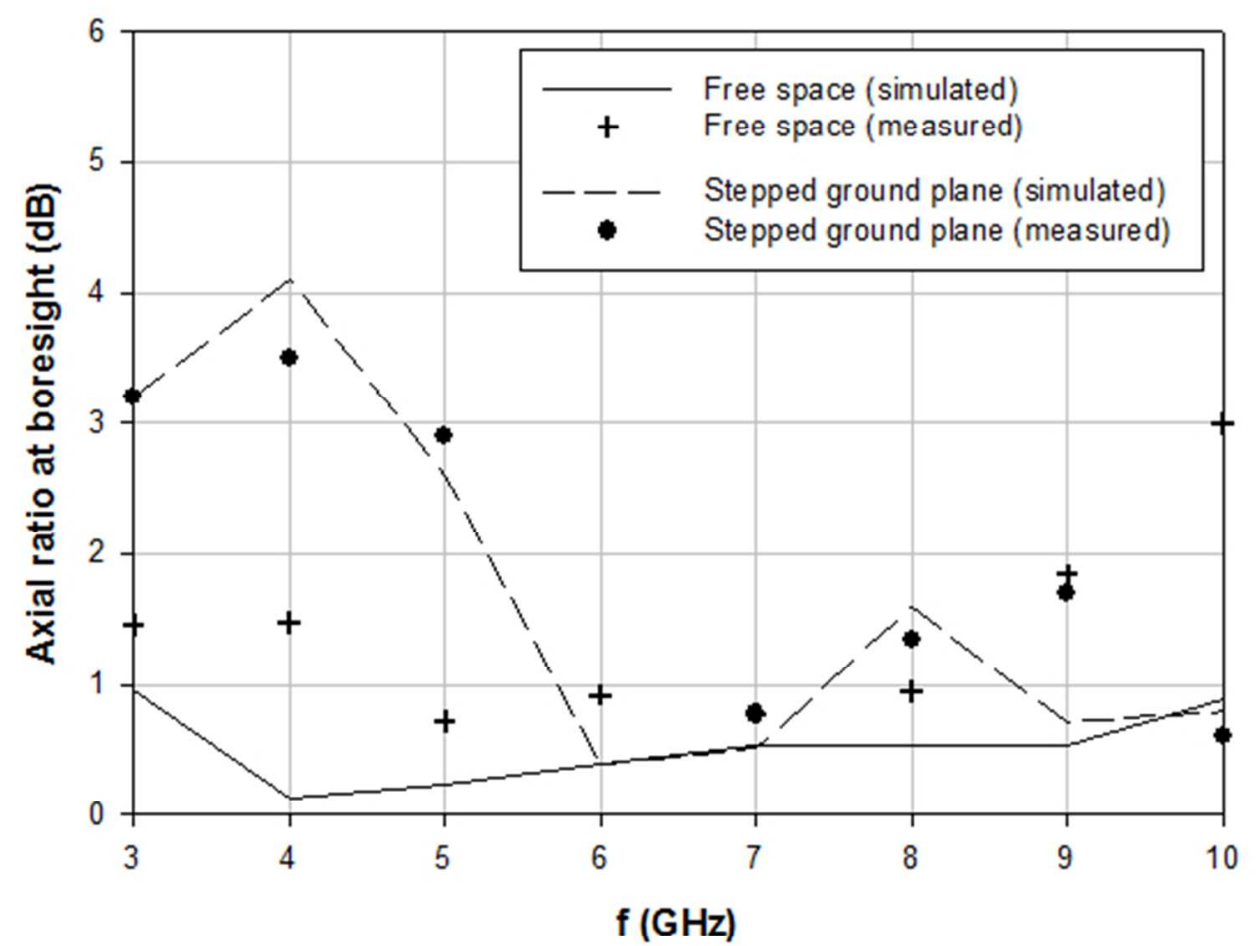

Figure 7. Predicted and measured axial ratio at boresight of spiral antenna in free space and stepped ground plane.

$149 \times 123 \mathrm{~mm}(96 \times 96 \mathrm{DPI})$ 


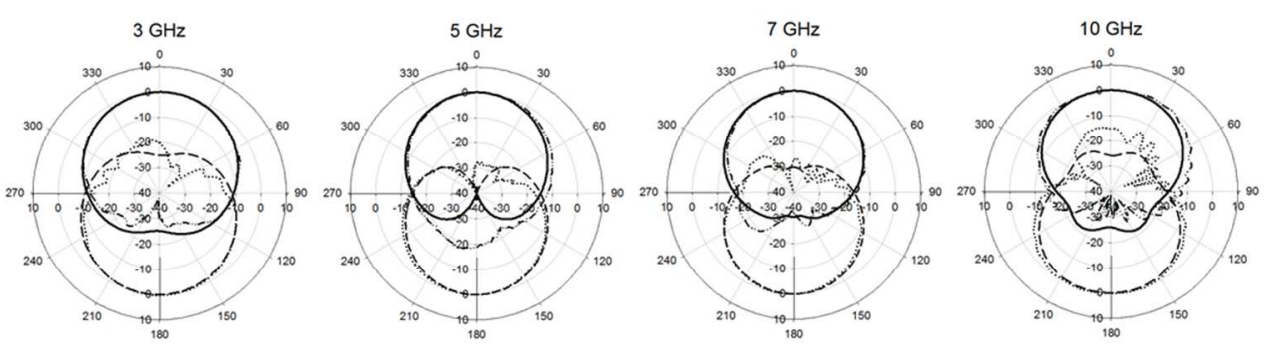

(a) Free space

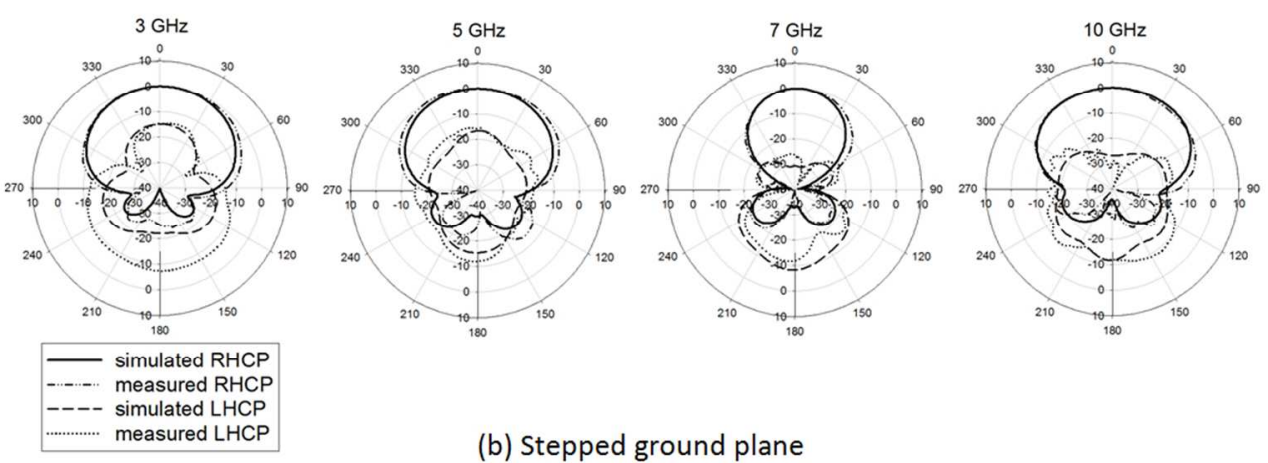

Figure 8. Normalized predicted and measured right-hand circular polarized and left-hand circular polarized beams generated by the spiral antenna at $\phi=0^{\circ}$ cut in (a) free space and with (b) stepped ground plane at frequencies $3 \mathrm{GHz}, 5 \mathrm{GHz}, 7 \mathrm{GHz}$ and $10 \mathrm{GHz}$.

$287 \times 233 \mathrm{~mm}(96 \times 96 \mathrm{DPI})$ 